\title{
Analysis of the Daylight Performance of Window Integrated Photovoltaics Systems
}

\author{
Yanyi Sun ${ }^{1 *}$, Dingming Liu ${ }^{1}$, Jan-Frederik Flor ${ }^{1}$, Katie Shank ${ }^{2}$, Hasan Baig ${ }^{2}$, Robin Wilson ${ }^{1}$, \\ Hao Liu ${ }^{1}$, Senthilarasu Sundaram ${ }^{2}$, Tapas K. Mallick ${ }^{2}$, and Yupeng $\mathrm{Wu}^{1 *}$ \\ ${ }^{1}$ Department of Architecture and Built Environment, University of Nottingham, Nottingham, UK \\ ${ }^{2}$ Environmental and Sustainability Institute, University of Exeter, Penryn, UK \\ *Corresponding authors’ Emails: Yanyi.Sun@nottingham.ac.uk (Yanyi Sun); Yupeng.Wu@nottingham.ac.uk
}

(Yupeng Wu)

\begin{abstract}
Integrating photovoltaics into windows provides the possibility of including an additional function of energy production to a conventional building fenestration component. There is no doubt that electrical power can be generated on-site. However, the effect of PV windows on the indoor luminous environment of the space served by them has not been comprehensively researched. This paper investigated the daylight performance of integrating four types of photovoltaics (semi-transparent thin film Cadmium telluride (CdTe) solar cells with $10 \%$ and $50 \%$ transparency, crystalline silicon solar cells with and without crossed compound parabolic concentrators (CCPC)) to a window of a typical south-facing office under different Window-to-Wall Ratios (WWRs). Annual useful daylight illuminance (UDI), daylight uniformity ratio (UR) and daylight glare probability (DGP) have been analysed based on dynamic simulation using RADIANCE. The simulation results show that windows integrated with crystalline silicon cells and CCPC optics have the potential to provide best daylight availability when compared with standard double glazed windows and other tested PV window prototypes, if it is applied to rooms with large WWRs (e.g. $60 \%$ or $75 \%$ WWR) at high latitudes (e.g. city of Harbin). Its application also improves the uniformity of daylight spatial distribution and eliminates the risk of glare. Semi-transparent CdTe PV window with $10 \%$ transparency can also improve the percentage of working hours that fall into UDI 5002000lux range, however, it will result in the most sharp illuminance contrasts within the room. Applying all of these tested PV windows can effectively reduce the possibility of glare.
\end{abstract}

Keywords: PV windows; Daylight performance; RADIANCE; UDI; UR and DGP 


\section{Introduction}

Integrating photovoltaics into building windows has been increasingly seen in modern building designs. This is due to its offer of: on-site energy generation; taking advantage of the building façade areas, and maintaining window transparency [1]. It may also play a role of shading and in doing so, regulate the transmitted sunlight to reduce building cooling demands [2]. The electricity generations and energy consumption savings lead to reduced energy cost and $\mathrm{CO} 2$ emission to benefit the ultimate end users and the environment [3,4]. The solar cells that can be used on windows or glazing façade include crystalline silicon solar cells (e.g. mono-crystalline, poly-crystalline), thin film solar cells (e.g. amorphous silicon, multijunction thin film silicon, cadmium telluride (CdTe), and copper-indium-dieseline) and organic solar cells (e.g. organic PV, dye-sensitized solar cells) [5].

In relation to PV window application, crystalline silicon solar cells present relatively high cell and module efficiency, however, when integrating them into windows, light transmission through the modules can only be achieved by altering the spacing between the cells as the cells are opaque. Compared to crystalline silicon solar cell windows, thin-film and organic solar cell windows can achieve a uniform appearance and semi-transmittance for daylight without casting shadows inside the room it served [6] [7] [8] [9]. Skandalos et al. [10] studied and compared the optical and thermal properties, as well as the thermal performance of a-Si and c-Si PV windows under a typical warm Mediterranean climate using TRNsys. Their results show the overall energy efficiency depends on solar cell coverage ratio and the electrical load connection. The optimal cover ratio was found to be 1 for a-Si and 0.8 for c-Si PV corresponding to maximised energy saving potential. Kapsis [11] investigated the annual daylight performance of poly-Si, a-Si and OPV windows using DAYSIM under cooling dominated continental climate. They concluded that semi-transparent photovoltaic modules with $10 \%$ visible effective transparency gives the lowest annual end-use electricity consumption. Cheng et al. [12] investigated the daylight and overall energy performance of PV windows with different PV cell coverage ratios, window-wall-ratios (WWR) and orientations in the cold region of China using EnergyPlus and DAYSIM. Their simulation results suggest that an optimal PV window design is that of $30 \%$ cell coverage ratio and $30 \%$ $40 \%$ WWR for south facing application.

In order to improve the efficiency of window integrated PV systems and reduce the usage of expensive solar cell material [13], concentrating photovoltaics (CPV) systems developed and implemented for building windows have been researched in recent years [14] [15] [16] [17] 
[18] [19]. CPV window applications include solar cells and some small pieces of optical element, which can collect and concentrate sunlight onto the solar cells. The compound parabolic concentrator (CPC) is one of the most attractive solutions for CPV windows because the CPC, as a low concentration optic, can achieve larger acceptance angles and eliminate the need for sun tracking equipment [20]. Sellami and Mallick [21] investigated the theoretical optical efficiency and the optical flux distribution at the photovoltaic cell of a 3-D Crossed Compound Parabolic Concentrator (CCPC) for different incidence angles using a 3D ray-tracing method. The results indicate that CCPC is an ideal concentrator for an acceptance angle equal to $30^{\circ}$ and a geometrical concentration ratio equal to 3.6. However, the optical flux distribution at the exit aperture is not uniform, which may consequently cause hot spots with decreased efficiency of solar cells. Cooper et al. [22] investigated the optical performance of a CPC with circular and various polygonal apertures by ray-tracing method. Their results suggest that the flux distributions at the exit aperture of polygonal CPCs was less uniform than that of the circular CPC. Baig et al. [18] evaluated detailed performances of a Square Elliptical Hyperbolae (SEH) based concentrator for building integration using modelling and indoor experiments. This system was found to have an optical efficiency of $40 \%$ with a relative wide acceptance angle, thus enabling sunlight capture throughout the day from both direct and diffuse radiations.

It is evident that replacing conventional windows by PV windows would result in power generation and energy conservation, leading to economic benefits of energy cost saving and environmental benefits of carbon cutting. However, there is little in the literature that investigates the quantity, quality and distribution of daylight that passes through these PV window systems and illuminates the inside space, especially for these applications of concentrating photovoltaics (CPV). The daylight performance may greatly affect its occupants' health, mood, activity and work efficiency [23]. Thus, further investigation is required to reveal how will the integration of solar cells and associated components (e.g. concentrating optics) shape the daylight performance of the buildings they are applied to. This would provide essential information for architects, designers, engineers and assist them to design and apply window integrated photovoltaics appropriately and correctly.

This paper provides a comprehensive picture of daylight performance when applying different types of window integrated photovoltaics to a typical office using dynamic simulation. In the simulation, glazing integrated thin-film semi-transparent CdTe solar cells with various transparency, and glazing integrated with crystalline silicon solar cells, with and 
without CCPC optics, have been investigated and compared with conventional double glazed window. A cellular office room with various window-to-wall ratios is modelled in RADIANCE to demonstrate these window systems' building application. Illuminance distribution is calculated for $1 \mathrm{~h}$ time-steps over the course of a year. The resultant illuminances were subsequently used to calculate advanced metrics (e.g. UDI, DGP and UR), which are used to quantify the indoor luminous environment severed by these window systems. The chosen window systems have also been investigated under different climate conditions to provide an indication of how site-specific variables influence performance.

\section{Tested prototypes of window integrated Photovoltaic systems}

In this research, four prototypes of Photovoltaic glazing systems were investigated to explore their effect on daylight performance when applying them to building windows. Their daylight performances have been compared with that of a reference double glazed window. As shown in Figure 1, the window prototypes investigated in this research include: a) double-glazed window (labelled as 'DG' in preceding discussions); b) semi-transparent thin film CdTe PV double-glazing with $10 \%$ transparency (labelled as '10\%_CdTe PVG' in preceding discussions); c) semi-transparent thin film CdTe PV double-glazing with 50\% transparency (labelled as '50\%_CdTe PVG' in preceding discussions); d) double-glazing system integrated with normal crystalline silicon solar cells (labelled as 'flat_si PVG' in preceding discussions); and e) double-glazing system integrated with crystalline silicon solar cells and embedded crossed CCPC (labelled as 'CCPC+si PVG' in preceding discussions).

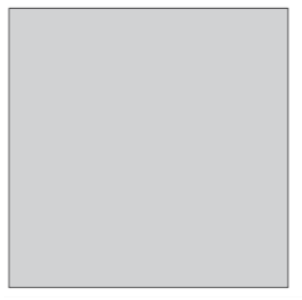

(a) DG
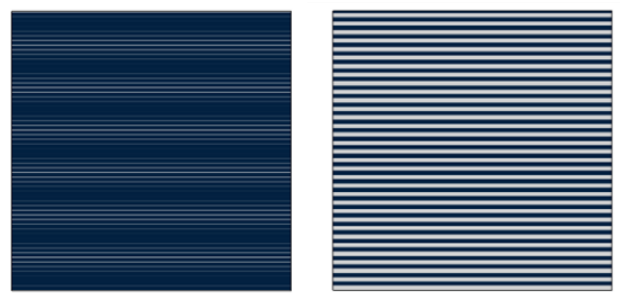

(b) $10 \% \_C d T e$ PVG (c) $50 \% \_C d T e$ PVG

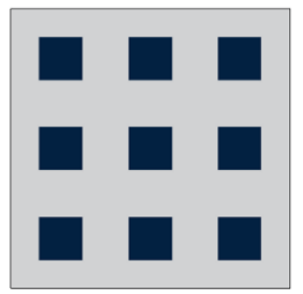

(d) flat_si PVG

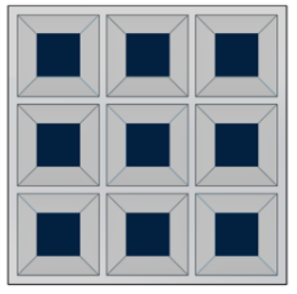

(e) $\mathrm{CCPC}+$ si PVG

Figure 1. Schematic diagram of window systems in research.

\subsection{Configurations of these tested window systems}

Figure 2 shows the pictures and diagrams of the configurations of these tested window systems. DG composed of two $4 \mathrm{~mm}$-thick float glass panes and a $20.06 \mathrm{~mm}$-wide cavity filled with air (shown in Figure 2(a)). The $10 \%$ or $50 \%$ CdTe PVG and the flat silicon PVG had similar configurations. They composed of two layers with a $15.86 \mathrm{~mm}$-wide air cavity. 
The outer layer consists of two 4 mm-thick float glass panes sandwiching CdTe solar cells or crystalline silicon solar cells (shown in Figure 2(b)) while the inner layer is a normal $4 \mathrm{~mm}$ thick glass. The other was a double-glazing unit with CCPC optics and crystalline silicon solar cells in the air cavity between the two glazing panes. From the outer layer to the inter layer, it composed of $4 \mathrm{~mm}$-thick float glass panes, $1.5 \mathrm{~mm}$-thick silicone encapsulant i.e. Sylgard, 18.16 mm-CCPC optics made by glass from Optical Lens Solutions [17], $0.2 \mathrm{~mm}$ thick Sylgard, $0.2 \mathrm{~mm}$-thick crystalline silicon solar cells and $4 \mathrm{~mm}$-thick float glass panes.
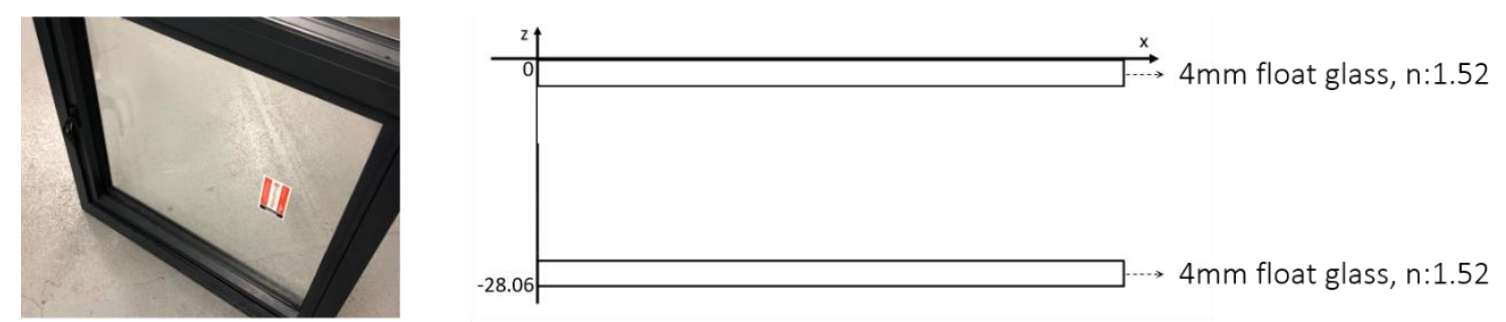

(a) DG
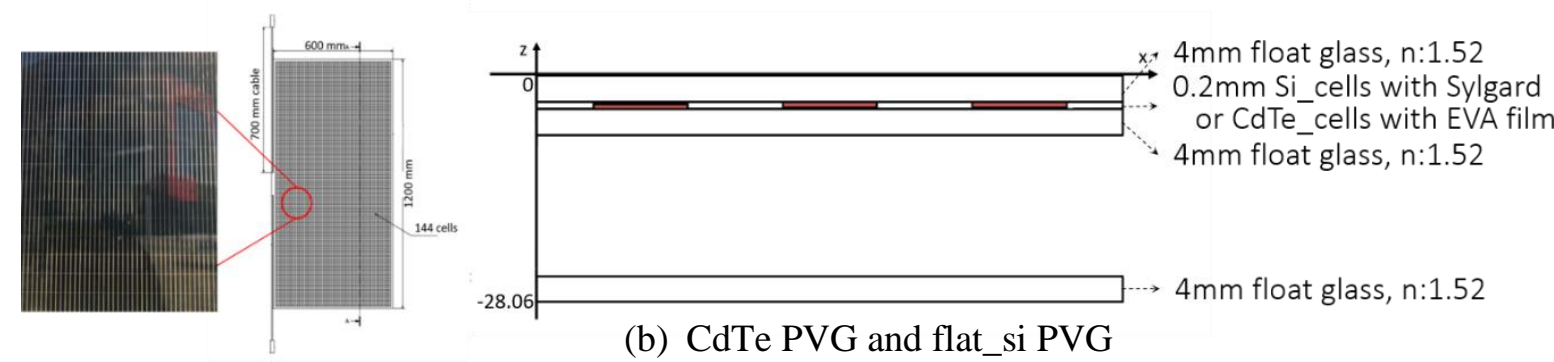

(b) CdTe PVG and flat_si PVG
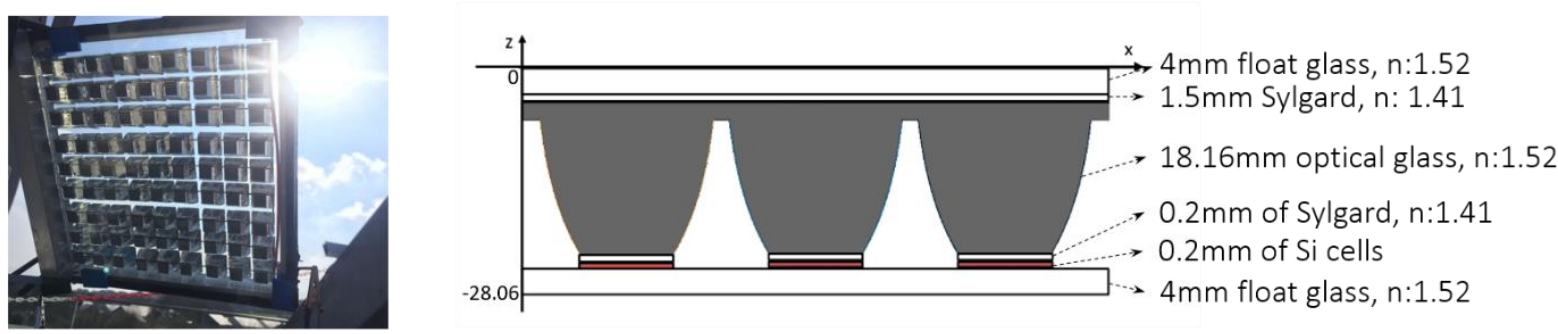

(c) $\mathrm{CCPC}+\mathrm{si} \mathrm{PVG}$

Figure 2. Pictures of these prototypes of the tested window systems (left) and their configurations (right)

\subsection{BSDFs of these tested window systems}

Based on the geometry and material optical properties of these window systems, they were optically characterized by Bidirectional Scattering Distribution Function (BSDF) using the ray tracing program that embodied within RADIANCE (i.e. genBSDF). The generated BSDF files, which define coefficients to allocate light from each exterior direction to each interior direction, were subsequently used in the annual simulation process.

In this study, the BSDF of each window prototype is based on Klems division, which comprises $145 \times 145$ matrices for representing the transformations of solar and daylight rays. 
This is a primary format for RADIANCE. Each matrix describes reflectance or transmittance distribution in the outgoing hemisphere for each incident angle of the incoming hemisphere [24]. Figure 3 (b) (f) demonstrates the angularly resolved transmission of each tested window prototype using an example of one incident angle from the incoming hemisphere i.e. the incident angle highlighted in yellow in Figure 3 (a). As can be seen in Figure 3 (b) (d), for DG, $10 \%$ _CdTe PVG and 50\% CdTe PVG, scattering of daylight rays cannot be observed. The significant differences between them are the overall hemispherical transmittance. The hemispherical transmittances, for the specific incident angle, are $72.1 \%$ for DG, $13.3 \%$ for $10 \%$ _CdTe PVG and $36.6 \%$ for $50 \%$ CdTe PVG. For flat_si PVG, as shown in Figure 3 (e), the transmitted daylight is slightly scattered by redirection of rays when passing through the glazing integrated with flat crystalline silicon solar cells. The overall hemispherical transmittance is $57.1 \%$ for the example incident angle. For a window integrated with CCPC optics and crystalline silicon solar cells, the transmitted light is well scattered as shown in Figure 3 (f), while the overall hemispherical transmittance is $41.5 \%$ for the demonstration incident angle.

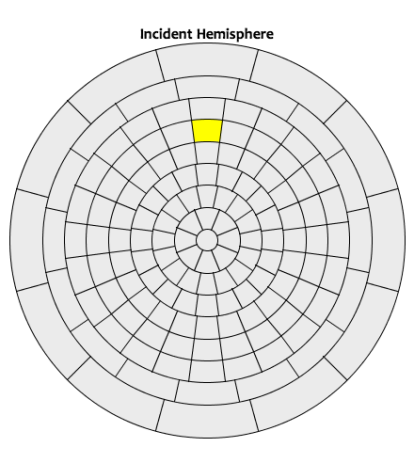

(a) Incident hemisphere

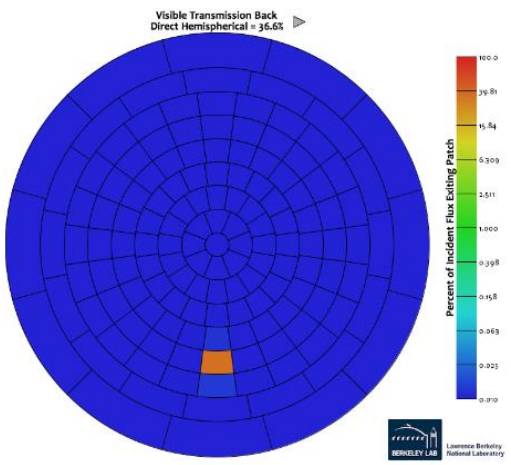

(d) $50 \%$ CdTe PVG

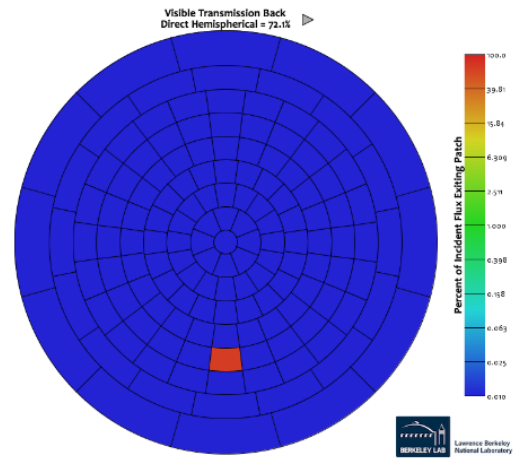

(b) DG

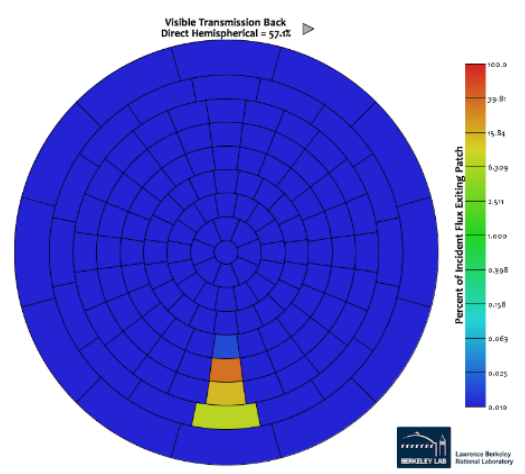

(e) flat-si PVG

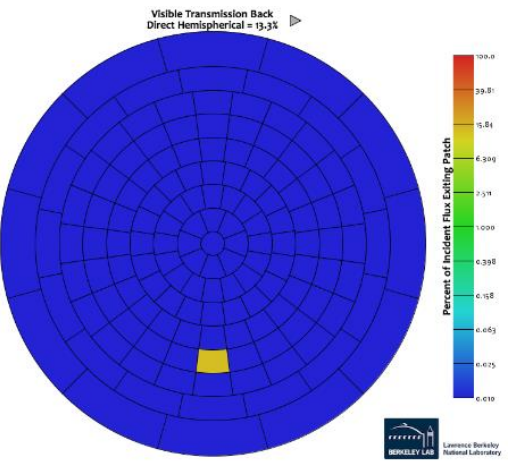

(c) $10 \% \_C d T e$ PVG

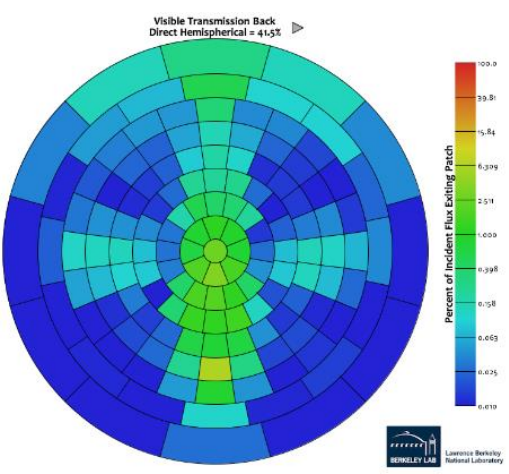

(f) $\mathrm{CCPC}+$ si PVG

Figure 3. BTDFs of the tested window systems: an example of one incident angle

\section{Modelling methodology}


To demonstrate the effect of applying different PV windows on the daylight performance of the indoor spaces, a typical south-facing office with various Window-to-Wall Ratio (WWR) was simulated in RADIANCE ( $\mathrm{v}$ 5.1) using a validated model [22]. The daylight performance predictions in terms of daylight availability and daylight comfort can be performed using simulation results for $1 \mathrm{~h}$ time-steps over the course of a year. Three representative cities in China (Harbin, Shanghai and Guangzhou) were selected in this research. The chosen PV windows have been investigated mainly based on the climate of Shanghai (i.e. $31.2^{\circ} \mathrm{N}, 121.5^{\circ} \mathrm{E}$ ). This is a city located in the central China with a typical climate of hot summer and cold winter [2]. Harbin (i.e $45.8^{\circ} \mathrm{N}, 126.5^{\circ} \mathrm{E}$ ) and Guangzhou, (i.e. $23.1^{\circ} \mathrm{N}, 113.3^{\circ} \mathrm{E}$ ) are two cities located in the farthest north and south regions in China. They were considered to provide an indication of how site-specific variables (e.g. local latitude) influence performance.

\subsection{Simulation method}

RADIANCE, which employs a backward ray-tracing method, was used to predict the daylight performance of a space served by PV windows. A "Three-phase method", which is commonly employed in the daylight simulation of complex fenestration systems [24], is employed in this research. Using this method, the angularly resolved transmissions and reflections for a complex window system (i.e. BSDF) are included in the annual calculation process. Meanwhile, hourly based annual climate data, which includes direct sunlight and diffuse skylight, are also embodied in the daylight performance prediction. The accuracy of the simulation tool and the simulation method has been validated by several studies [25] [26] [27].

\subsection{Prototype office geometry and modelling}

A south-facing office with dimensions $2.9 \mathrm{~m}$ (width) $\times 4.4 \mathrm{~m}$ (depth) $\times 3.3 \mathrm{~m}$ (height), was chosen for the simulation (Figure 4). The office surfaces were treated as perfectly diffuse with typical visible reflectance values of $30 \%$ (floor), $80 \%$ (walls) and $80 \%$ (ceiling). It was assumed there were no surrounding buildings, vegetation or other obstructions outside the office. An exterior ground plane with RGB reflectance of $(0.4,0.4$ and 0.1$)$ [24] was used to represent a grass green colour in the external environment.

A total of 45 calculation points arranged in a grid with $0.5 \mathrm{~m}$ interval between each node over the working plane (i.e. $0.75 \mathrm{~m}$ above floor level) were used in the model to determine the illuminance distribution as illustrated in Figure 5. The room was assumed to be used as a 
private office for two people, with one positioned near the window and the second at the back of the room (Figure 4). As glare caused by daylight is less likely to be an issue at the back of the room, the glare evaluation was based on a view point representing the occupant near the window. This was located at a distance of $1.2 \mathrm{~m}$ from the window and at a height of $1.2 \mathrm{~m}$ above the floor on the centre axis of the room; facing west and east as shown in Figure 5.

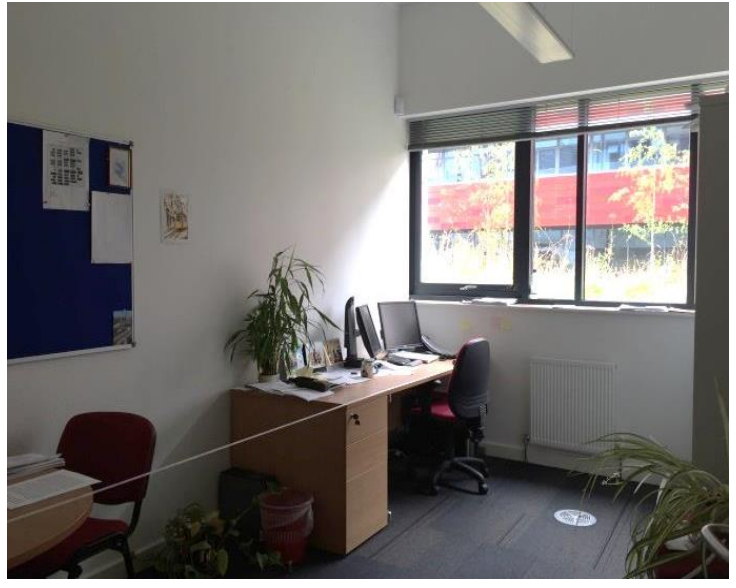

Figure 4. Photo of test room.

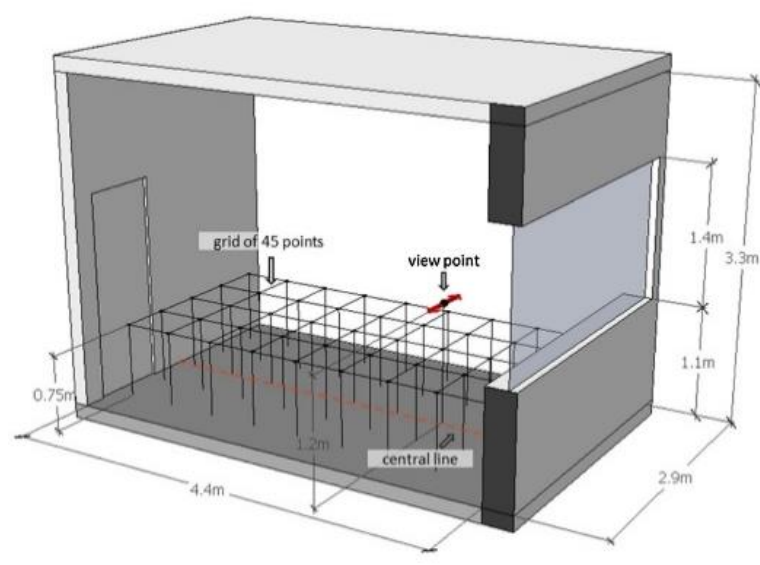

Figure 5. Schematic diagram of prototype office and test points

\subsection{Design scenarios in this research}

To explore the effect of PV windows on the indoor daylight availability and quality of a room with different sizes of opening, four design scenarios with different Window-to-wall ratios (WWRs) were considered in this research. Window-to-wall ratio is the ratio between the area of window and the area of the whole façade [28], which is a dominative façade design factor that decides the daylight and energy performance of a building [29]. As shown in Figure 6, WWRs of $30 \%, 45 \%, 60 \%$ and $75 \%$ were considered in this research to represent small,

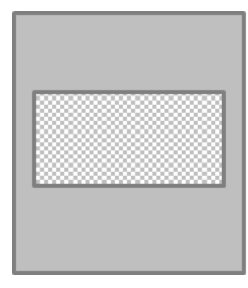

(a) $30 \% \mathrm{WWR}$

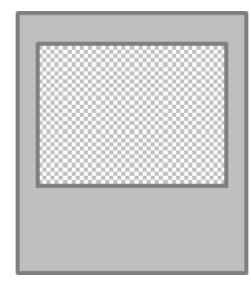

(b) $45 \%$ WWR

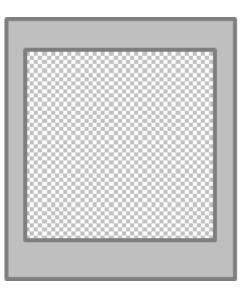

(c) $60 \% \mathrm{WWR}$

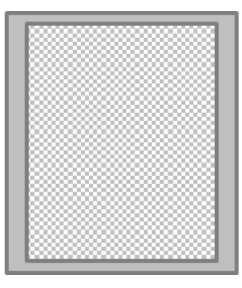

(d) $75 \% \mathrm{WWR}$

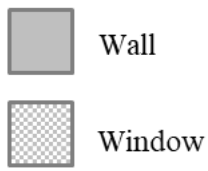

Figure 6. Tested Window-to-Wall Ratios (WWRs)

medium, large or extra-large windows respectively. 


\subsection{Metrics for evaluating daylight availability and daylight comfort}

The resultant daylight illuminance levels obtained from RADIANCE simulations of different PV windows in the office with various WWRs have been analysed using three metrics. These include: useful daylight illuminance (UDI), which is a widely adopted dynamic metric for daylight availability assessment; daylight illuminance uniformity ratio (UR) and daylight glare probability (DGP), which are two metrics used to evaluate daylight comfort level of the indoor space.

UDI is used to quantify daylight autonomy according to occupant response to varying daylight illumination [30]. The predicted illuminance level at points along the centre line of the room between the window and the end wall achieved during the working hours in a year were categorised into three acceptance threshold bins. These include: 1) when the daylight illuminance of a specific time is lower than 100 lux, which means daylight alone is insufficient either as the sole source of illumination or to contribute significantly to offsetting use of artificial lighting, the result lands in an undersupply UDI bin; 2) when daylight illuminance of a specific time is higher than 2000 lux, which indicates that the daylight is likely to lead to visual and/or thermal discomfort, the result lands in an oversupply UDI bin; and 3) when the daylight illuminance is in a range of 100-2000 lux, which is considered to provide useful levels of illuminance, the result lands in a useful UDI bin (labelled as 'UDI 1002000 lux' in preceding discussions). In order to provide a more detailed picture of the useful bin, UDI 100-2000 lux can be further subdivided into two ranges: a desired range, i.e. values of illuminance in the range of 500-2000 lx (labelled as 'UDI 500-2000 lux' in preceding discussions), where a typical office design illuminance is met and is not exceeded to the point where glare is highly likely [31]; and a sub-desired range, i.e. values of UDI in the range of $100-5001 x$, where there is an increasing likelihood that occupants will resort to supplementary lighting to meet their illumination needs.

UR, which can be obtained from the minimum and area-weighted average illuminance values [32] from the 45 daylight study points (Figure 5), is used as a metric associated with daylight distribution. In this research, thresholds of $0.2,0.3,0.4,0.5$ and 0.6 were used to split the generated UR into 6 bins. BREEAM recommends that the uniformity ratio must exceed 0.3 to be classed as good practice [33].

Glare occurs when the luminance level within the field of view exceeds the brightness that the human eye can adapt to [34]. To evaluate glare, and in particular discomfort glare caused 
by daylight, the daylight glare probability (DGP) technique is preferred. In the purpose of conducting dynamic analysis of DGP over a period of a year, a quick and simplified calculation method to obtain DGP based on the vertical illuminance at the observer was introduced and validated by Wienold and Christofferen [34] [35]. Thresholds of 0.35, 0.40 and 0.45 can be used to divide the DGP results calculated for occupied hours of a year into four bins: lower than 0.35 is 'imperceptible' glare sensation, between 0.35 and 0.40 is 'perceptible' between 0.40 and 0.45 is 'disturbing', while higher than 0.45 is deemed 'intolerable' [34] [35] [36].

\section{Results and discussion}

\subsection{Renderings of room with various $P V$ windows}

In order to provide an intuitive impression of luminous environment in the office with various PV windows and the reference DG window, true colour and false colour visualisations for noon on a sunny summer solstice day (21st June) under the climate of Shanghai were generated and are shown in Figure 7. As can been seen, the room with normal DG suffers noticeable over-illumination while the PV windows can remit this to a certain degree. The presence of CCPC+si PVG provides the most homogenous distribution of daylight and creates the most harmonious luminous environment.

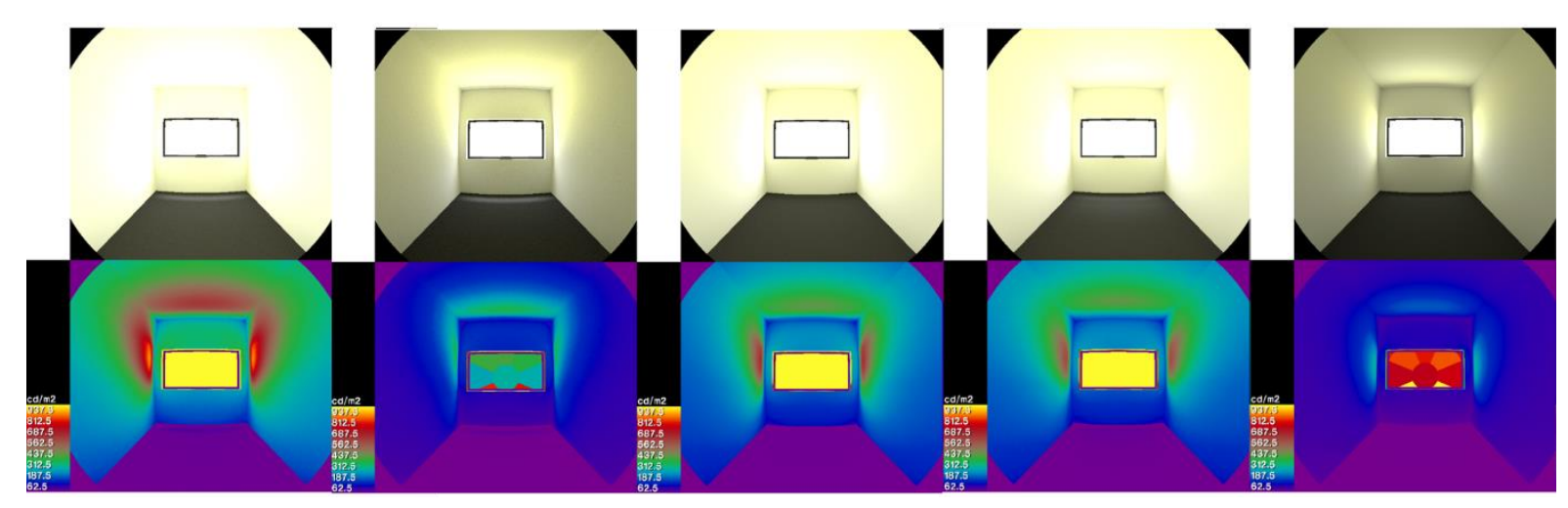

(a) DG

(b) $10 \%$ CdTe PVG

(c) 50\%_CdTe PVG

(d) flat_si PVG

(e) CCPC+si PVG

Figure 7. Renderings of room of $30 \% \mathrm{WWR}$ with various $\mathrm{PV}$ windows at 12:00 noon on summer solstice day (21/06) under the climate of Shanghai,

\subsection{Useful daylight illuminance}

Annual predictions were made for these four PV windows and the reference DG window at 4 different WWRs. Figure 8 shows the predicted useful UDI bin at points along the centre line of the room between the window and the end wall. 
As can be seen, 30\% WWR, 50\%_CdTe PVG and flat_si PVG windows provided improved useful daylight as more percentage of working hours fell within the useful UDI bin (UDI 100-2000 lux) when compared to the reference DG window. This is because both PV windows have a lower optical transmittance than that of the DG window, resulting in less working hours exposed to oversupplied daylight (i.e. illuminance higher than 2000 lux). The 10\%_CdTe PVG window, when compared with the DG window, slightly improve the daylight availability for the rear half of the room. However, it also caused a higher proportion of the working hours to be exposed to daylight oversupply (i.e. appearing in the UDI $>2000 \mathrm{~lx}$ bin) in the region close to the window. This is because the inclusion of thin film cells and the micro-gaps between each two cells can cause redirection of daylight rays. Consequently, a major portion of daylight rays fall on the area near to the window rather than penetrating deeper into the room. At the other extreme, CCPC+si PVG window provides a significant improvement over conventional DG for the half room near to the window where UDI 1002000 lux is in a range of $80.7 \% \sim 86.4 \%$ for the points closer than $2.7 \mathrm{~m}$ from the window. This is because the presence of CCPC+si PVG causes scattering of daylight and thus effectively eliminates the oversupplied daylight illuminance. For windows with WWR larger than $45 \%$, all four PV windows provide increased useful daylight for the whole room by replacing the conventional DG, while the $\mathrm{CCPC}+\mathrm{si} \mathrm{PVG}$ window offers the best performance. For example, when WWR is $75 \%$, the percentage of working hours where the UDI is in the useful range (UDI 100-2000 lux) along the rooms central line, increased from $10.5 \%$ to $51.1 \%$ for the DG window and from $56.3 \%$ to $90.1 \%$ for the CCPC+si PVG window.

However, if observations focus on the most desired UDI range, i.e. UDI 500-2000 lux, where daylight meets the requirement of illuminance for a typical office as the sole source, not all of the PV windows could provide improved daylight availability across the entire room under the climate of Shanghai. As shown in Figure 9, the improvements of UDI 500-2000 lux for applying 10\%_CdTe PVG, 50\%_CdTe PVG and flat_si PVG windows show similar tendency with that of UDI 100-2000 lux. However, applying the CCPC+si PVG window can only increase the percentage of working hours in UDI 500-2000 lux bin for the region near to the window and decreasing the working hours at the rear part of the room, when compared with the DG window. This is because the illuminance scattered daylight passing through the CCPC+si PVG window and falling at the rear part of the room is majorly in the range of 100500 lux. 


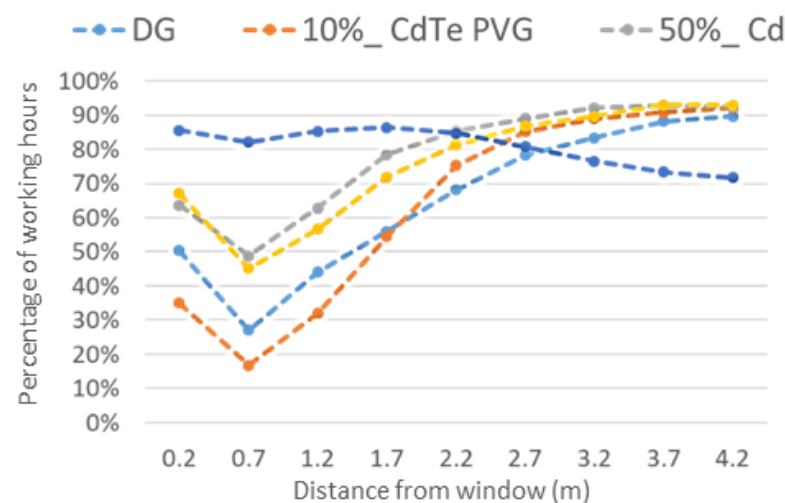

(a) $30 \% W W R$

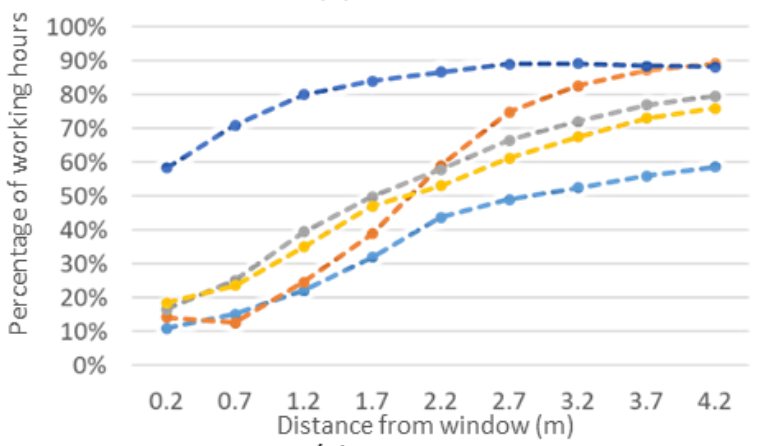

(c) $60 \% \mathrm{WWR}$

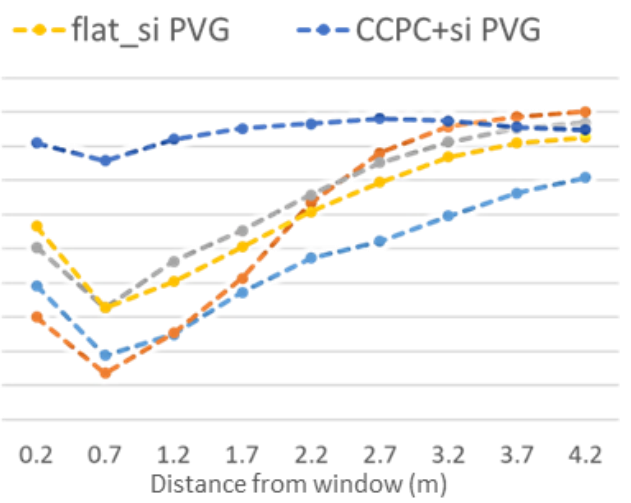

(b) $45 \%$ WWR

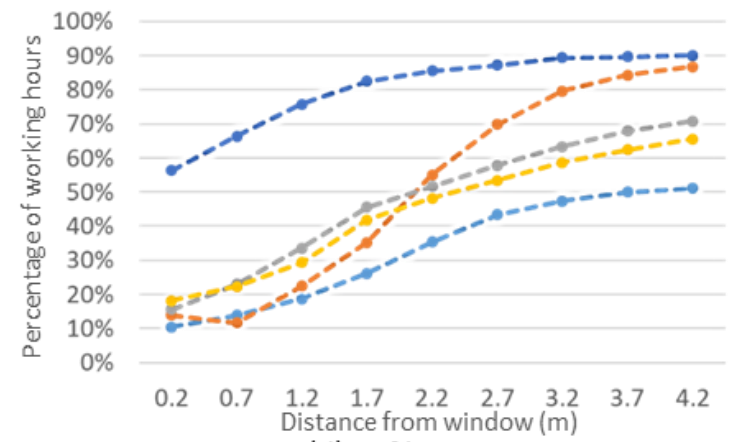

(d) $75 \% \mathrm{WWR}$

Figure 8. Annual UDI 100-2000lux distribution for room of 4 WWRs with various $P V$ windows under the climate of Shanghai

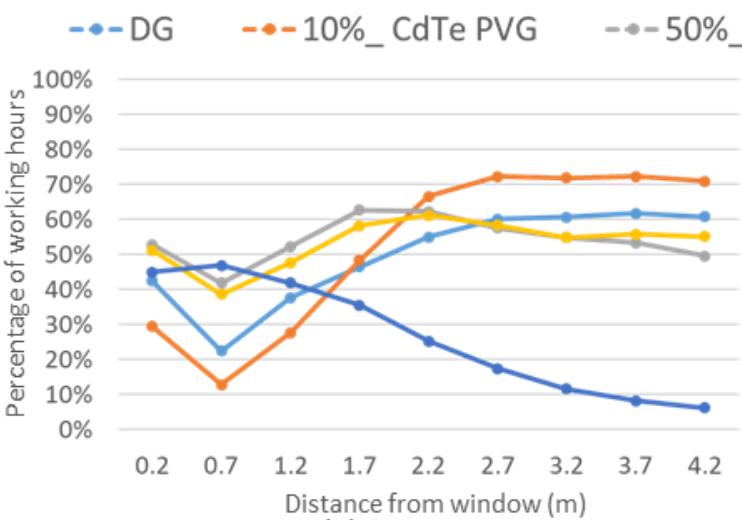

(a) $30 \%$ WWR

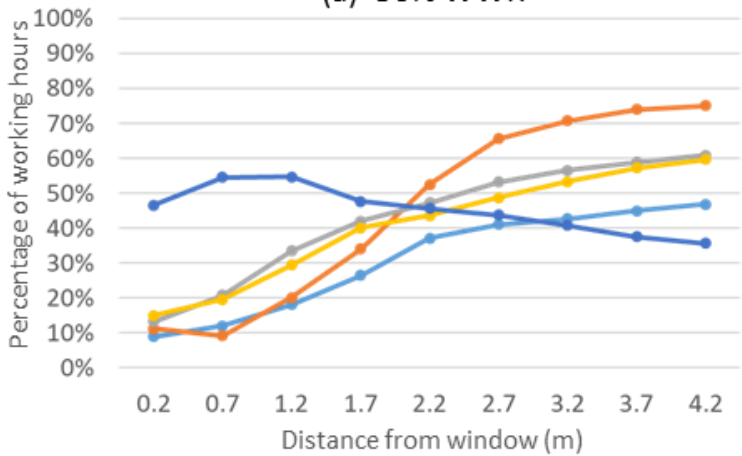

(c) $60 \% \mathrm{WWR}$

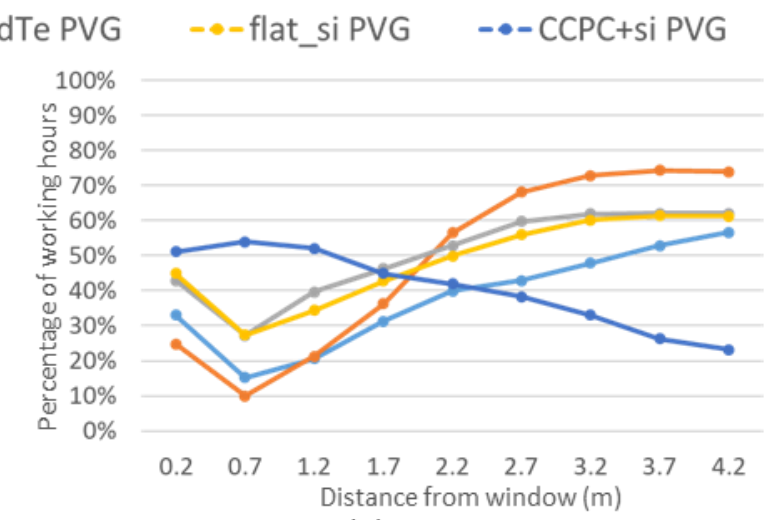

(b) $45 \%$ WWR

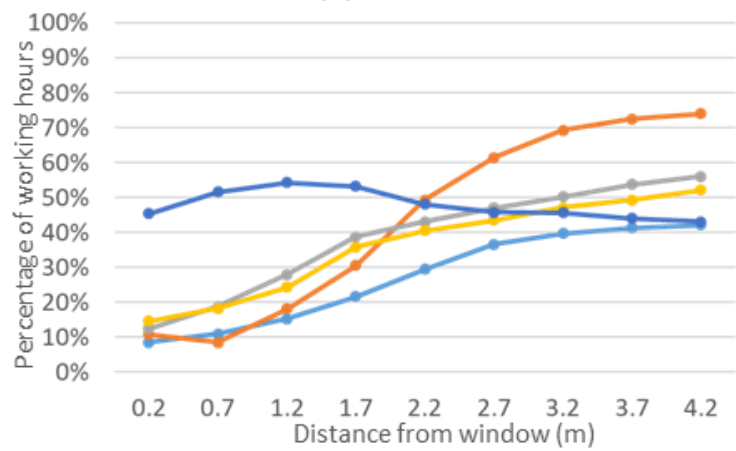

(d) $75 \%$ WWR

Figure 9. Annual UDI ${ }_{500-2000 l u x}$ distribution for room of 4 WWRs with various $P V$ windows under the climate of Shanghai 
The performance of the PV windows is likely to be influenced by the latitude of the site where they are implemented on. To further explore the UDI performance of these PV window prototypes under different latitude, simulations of PV windows' office application were performed using IWEC weather files for Harbin and Guangzhou, representing a city with a high latitude $\left(45.8^{\circ} \mathrm{N}\right)$ and a city with a low latitude $\left(23.1^{\circ} \mathrm{N}\right)$, respectively. Figure 10 and 11 show the distribution of desired UDI bins under different WWRs for the climates of Harbin and Guangzhou respectively.

For the climate of Harbin, the CCPC+si PVG window shows similar daylight performance with that of the $10 \%$ _CdTe PVG window when WWR is $30 \%$. In the region close to the window, they produce a higher proportion of the working hours within the UDI500-2000 lux bin. This percentage gradually reduces for points further than $1.7 \mathrm{~m}$ from the window. With the increase of WWR (i.e. WWR is higher than 45\%), the integration of CCPC+si PVG and 10\%_CdTe PVG windows can provide more desirable daylight for the room. The CCPC+si PVG gives rise to the highest percentage of working hours in the range of UDI500-2000 lux. For example, under $75 \%$ WWR, when replacing the DG window by the CCPC+si PVG, the proportion of UDI 500-2000 lux can be improved to approximately $26.0 \%$ and $62.3 \%$ of working hours. Applying the 50\%_CdTe PVG and the flat_si PVG window shows a similar tendency of improved UDI over the DG window as that under the climate of Shanghai for WWRs of $30 \%, 45 \%$ and $75 \%$. However, when WWR is $60 \%$, the presence of $50 \%$ CdTe PVG can provide more desirable daylight than the flat_si PVG window.

UDI performances of these PV windows and the reference DG windows under Guangzhou's climate are shown in Figure 11. For 30\% WWR, CCPC+si PVG and 10\%_CdTe PVG windows perform worse in the illuminance range of 500-2000 lux when compared with the DG window. Even for WWRs of $45 \%$ and $60 \%$, these two PV windows can only slightly improve the percentage of working hours falling in the $\mathrm{UDI}_{500-2000}$ lux bin for the area near to the window while resulting in a lower percentage of working hours in the rear area the office. For 75\% WWR, the daylighting performance of 50\%_CdTe PVG, flat_si PVG and CCPC+si PVG windows are similar as that of the DG window. The 10\%_CdTe PVG window can meanwhile slightly improve the most desired daylight availability in the region less than 2.7 $\mathrm{m}$ away from the window. 
-•-DG $\quad--10 \%$ CdTe PVG $\quad--50 \%$ CdTe PVG $\quad-$-flat_si PVG $\quad-\bullet-C C P C+$ si PVG
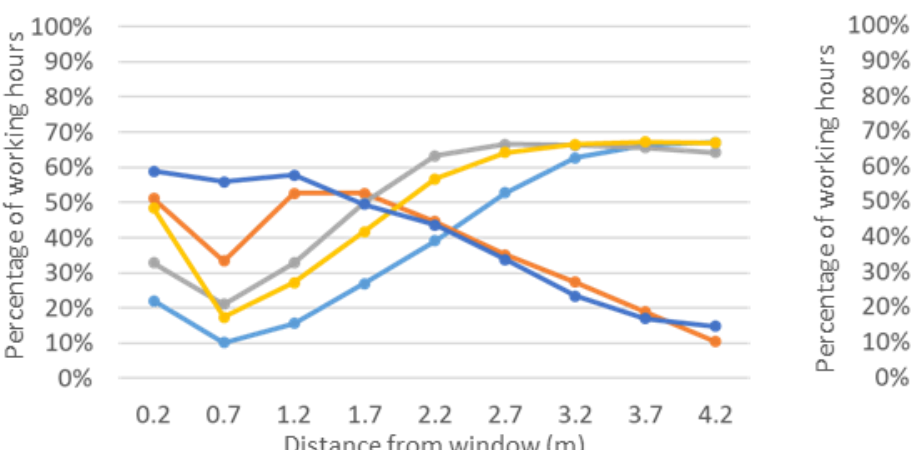

(a) $30 \%$ WWR

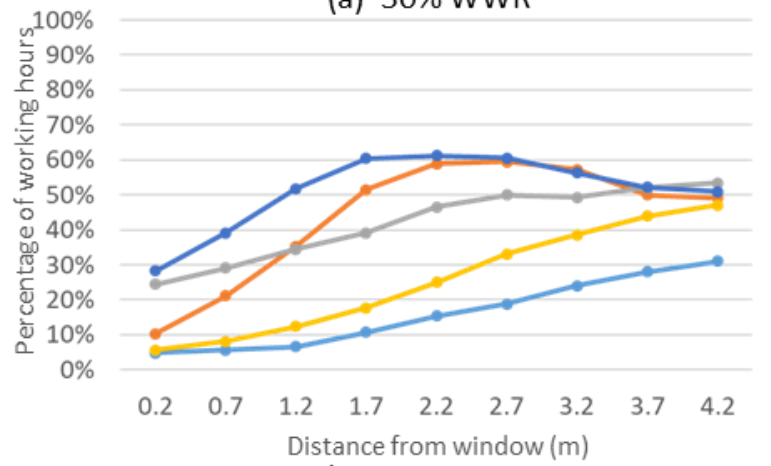

(c) $60 \%$ WWR

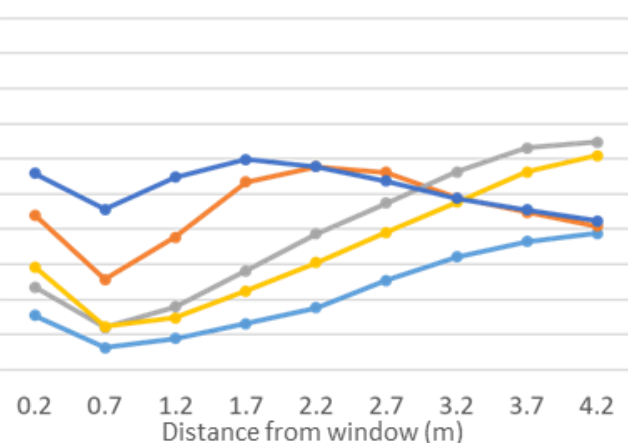

(b) $45 \%$ WWR

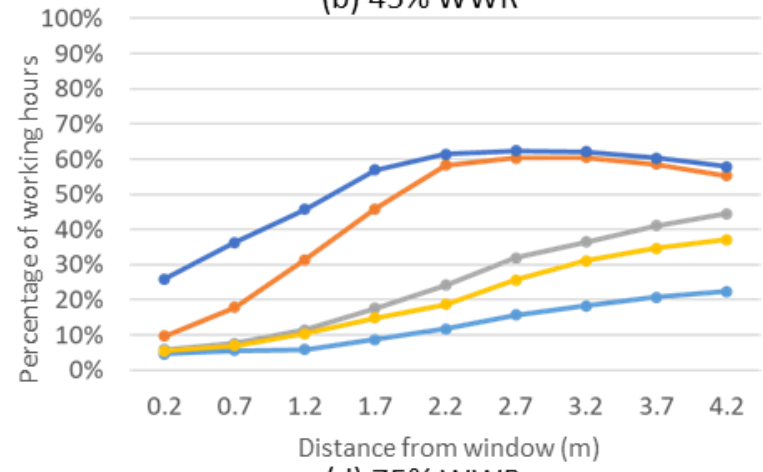

(d) $75 \% \mathrm{WWR}$

Figure 10. Annual UDI 500-2000lux distribution for room of 4 WWRs with various PV windows under the climate of Harbin

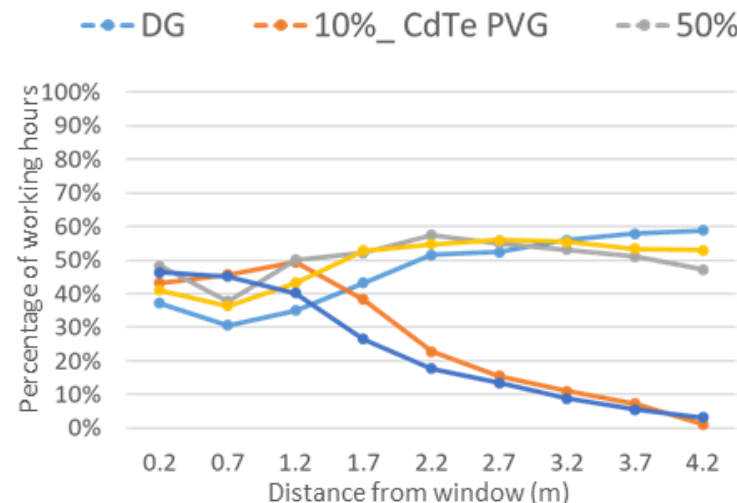

(a) $30 \%$ WWR

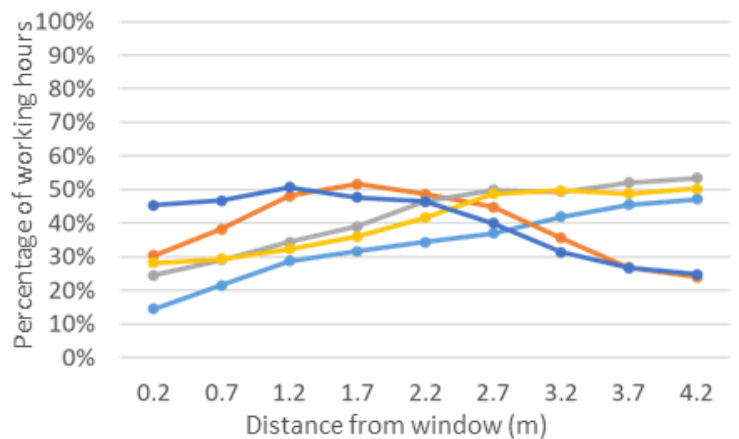

(c) $60 \%$ WWR

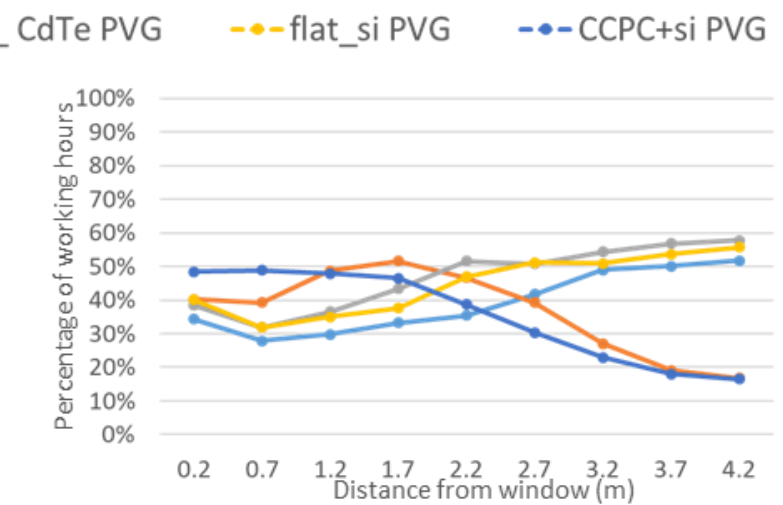

(b) $45 \%$ WWR

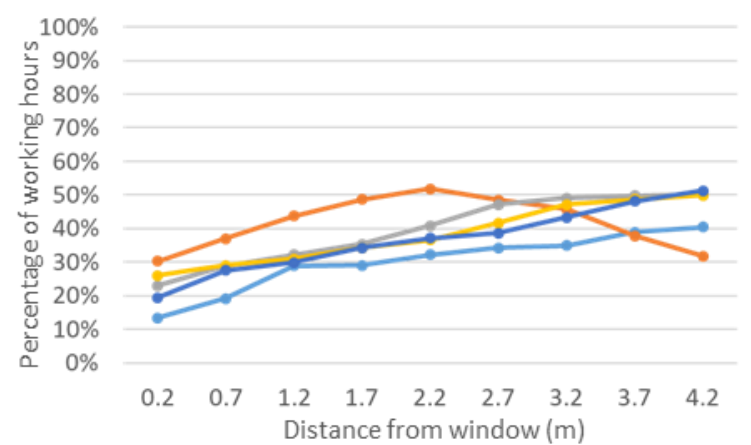

(d) $75 \%$ WWR

Figure 11. Annual UDI500-2000lux distribution for room of 4 WWRs with various PV windows under the climate of Guangzhou 


\subsection{Daylight uniformity Ratio}

The uniformity ratio (UR) of daylight is a metric used to represent the homogeneity of daylight distribution within a space. In this research, annual results can be obtained from the minimum and area-weighted average illuminance values from the 45 daylight study points at each hour for the four PV windows and reference DG window under the climate of Shanghai when the WWR is $60 \%$. BREEAM recommends that the uniformity ratio must exceed 0.3 to be classed as good practice [33], the higher the better. The percentages of working hours where UR< 0.3 for: DG, 10\%_CdTe PVG, 50\%_CdTe PVG, flat_si PVG and CCPC+si PVG windows, are $10.8 \%, 83.7 \%, 5.8 \%, 10 \%$ and $2.3 \%$ respectively. It is obvious that applying the 10\%_CdTe PVG window has a negative effect on the daylight uniformity of the indoor space, while 50\%_CdTe PVG and CCPC+si PVG windows can improve the daylight uniformity to a certain extent. These phenomena can also be proved by daylight illuminance contour plots as shown in Figure 13, which demonstrates the daylight illuminance distributions on the working plane in the office for various PV windows at 12:00 noon on summer solstice (21/06) and winter solstice (22/12) days under the climate of Shanghai when WWR is $60 \%$. The sharpest illuminance contrasts can be found incorporating the $10 \%$ CdTe PVG window. This can be explained by light passing through thin film cells and their microgaps: the daylight rays are redirected and a major portion of them falls on the area near to the window rather than penetrating deeper into the room.

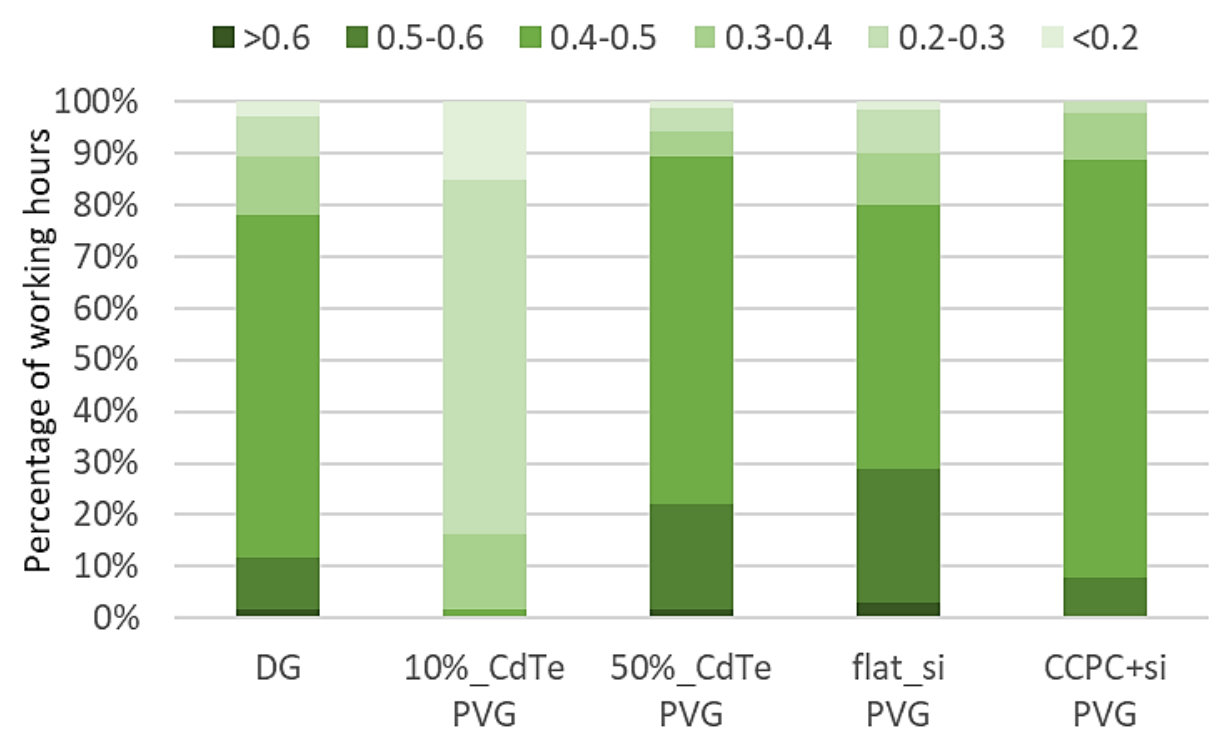

Figure 12. Daylight uniformity ratio of various PV windows with $60 \% \mathrm{WWR}$ under the climate of Shanghai 

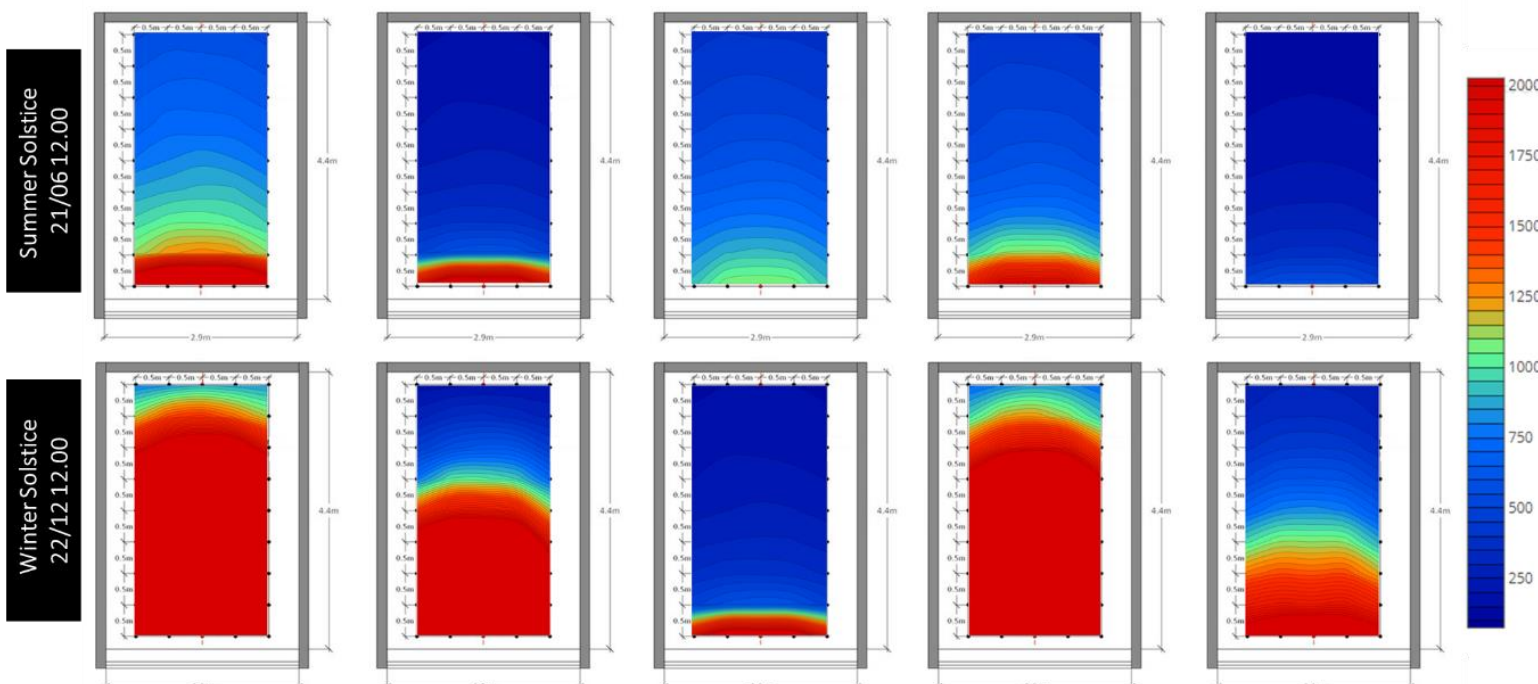

(a) DG

(b) $10 \% \_C d T e$ PVG

(c) 50\%_CdTe PVG

(d) flat_si PVG

(e) $\mathrm{CCPC}+$ si PVG

Figure 13. Contour plots of the daylight illuminance distributions at the working plane level in the office for various PV windows at 12:00 noon on summer solstice (21/06) and winter solstice $(22 / 12)$ days under the climate of Shanghai when WWR is $60 \%$

\subsection{Daylight glare probability}

Annual predictions of the DGP for PV windows and the reference DG window were conducted for the assumed occupant position near the window (1.2 $\mathrm{m}$ away from the window at $1.2 \mathrm{~m}$ height) under the climate of Shanghai when the WWR is $60 \%$. The results are shown in Figure 14. For the conventional DG window: $24.8 \%$ intolerable glare (DGP $\geq 0.45$ ), $13 \%$ disturbing glare $(0.4<$ DGP < 0.45$)$, and $11.8 \%$ perceptible glare $(0.35<$ DGP < 0.4$)$ of occupied hours was predicted. When PV windows were applied, significant improvement in the percentage of imperceptible glare $(\mathrm{DGP} \leq 0.35)$ is achieved. The figure increases from $50.4 \%$ of working hours for DG to $91.8 \%, 73.9 \%, 66.4 \%$ and $100 \%$ with the application of 10\%_CdTe PVG, 50\%_CdTe PVG, flat_si PVG and CCPV+si PVG window, respectively. To evaluate the suitability of the various windows for use in design, a criterion threshold relating to the effectiveness of the daylit environment was established. In so doing, a room can be classified as 'Best' practice for over 95\% of office working hours having imperceptible glare (DGP $\leq 0.35$ ), while a 'Good' practice means over 95\% of office working hours having glare weaker than perceptible [35]. As can be seen from Figure 14, at no point did the DG window come close to meeting these criterions. However, when CCPV+si PVG window is applied, the office has a 'Best' classification and when 10\%_CdTe PVG window is applied, the office has a 'Good' classification. 


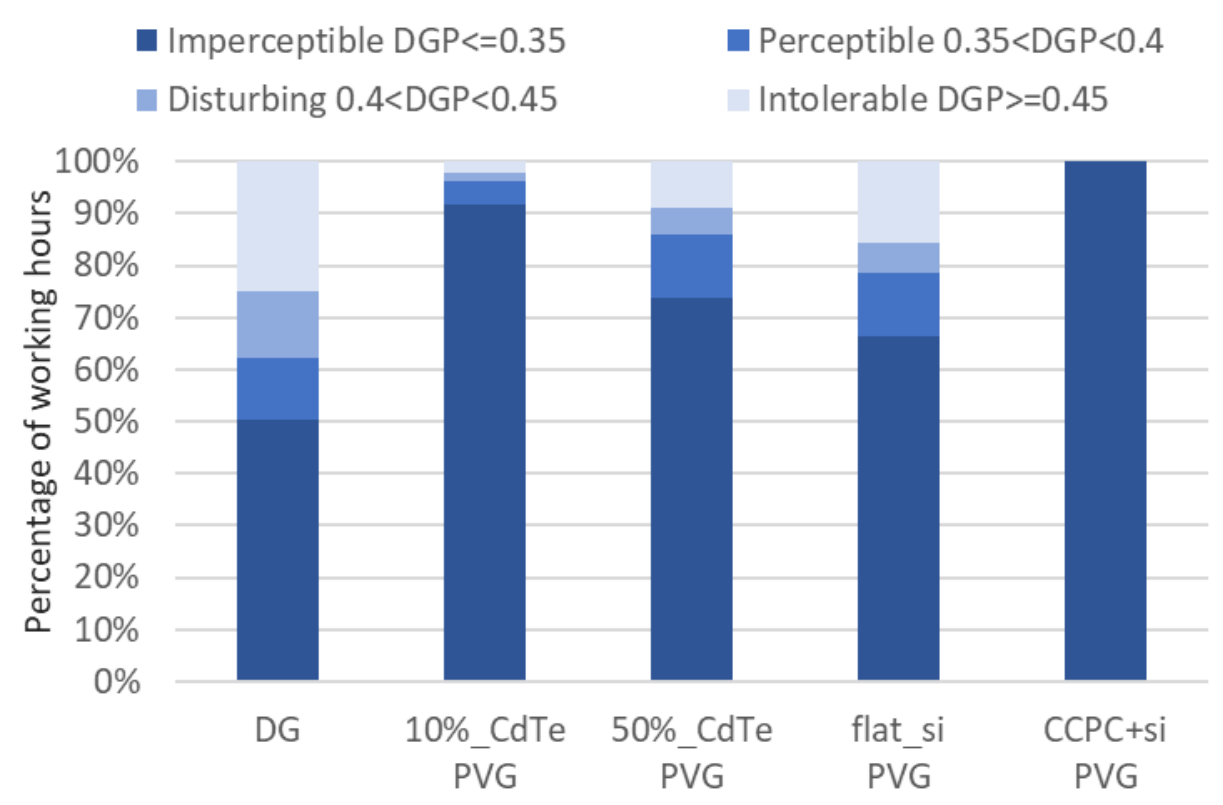

Figure 14. Daylight glare Pprobability (DGP) various PV with 60\%WWR under the climate of Shanghai

\subsection{Summary of the daylight performance of different $P V$ windows}

In summary, applying all of these tested PV windows can improve the daylight performance when compared with conventional double-glazing window units under the climates of Shanghai, Harbin and Guangzhou. Among them, integrating crystalline silicon solar cells with CCPC optics gives rise to the highest percentage of working hours that fall into the UDI 100-2000 lux range under the climate of Shanghai, and that into UDI 500-2000 lux range under the climate of Harbin, when WWR is larger than $45 \%$. This means it will be more applicable for higher latitudes with lower solar incident angles. This PV window prototype also provides the most uniform daylight spatial distribution when compared with other tested window systems and fully eliminates the risk of daylight glare. 10\%_CdTe PVG window provides improved daylight availability for all the tested climates when WWR is larger than $45 \%$, especially for $75 \%$ WWR scenario under Guangzhou's climate when other PV window prototypes are not meaningfully beneficial. However, it also results in less uniform daylight distribution inside the room and sharp illuminance contrasts. This is because, when passing through the solar cells and their micro-gaps, daylight rays are redirected and consequently falls on the area near the window other than penetrates deep into the room. Windows integrated with 50\%_CdTe PVG and flat_si PVG shows mediocre performance: minor improvement in daylight availability in nearly all of the tested scenarios, insignificant improvement in daylight uniformity and slight reduction in daylight glare probability. 


\section{Conclusions}

Window integrated photovoltaics have the potential to provide on-site power generation and regulate building energy consumption and thus contribute to the international aspirations of reducing building-related $\mathrm{CO} 2$ emission. However, relatively few studies exist regarding the daylight performance analysis of applying PV windows to buildings. In this guise, the luminous environment created by applying four types of window integrated photovoltaics systems, which are recently emerged on the market or showing a growing commercialisation prospect, have been numerically studied. RADIANCE was used for annual dynamic simulation and the resultant hourly illuminance was analysed with respect to key daylight availability and comfort metrics. A range of different WWRs and test locations have been considered to explore their performance under different design or site-specific scenarios. The following conclusions can be drawn:

1) In the perspective of reducing over-illuminate conditions, which is usually existed for conventional double glazing unit, applying all these types of PV windows could provide improvement to a certain degree. This is caused by the reduced visible transmittance with the presence of solar cells.

2) Window integrated crystaline silicon solar cells with CCPC optics has the potential to provide best daylight availability when compared with double glazed windows and other tested PV window prototypes. However, its application is competitive for high latitude (i.e. city of Harbin in this study) and large WWRs (i.e. $60 \%$ or $75 \%$ WWR in this study).

3) In most of the scenarios investigated in this research, 10\%_CdTe PVG window could provide improved daylight availability (i.e. UDI 500- 2000 lux). However, it results in less uniform daylight distribution inside the room.

4) 50\%_CdTe PVG, flat_si PVG and CCPC+si PVG can improve the uniformity of daylight distribution inside the tested office.

5) All of these tested PV windows can reduce the risk of glare caused by daylight but the CCPC+si PVG window provides the best performance.

This research has restricted itself to exploring the effect of PV windows on indoor luminous environment. Investigations of their electrical generation capacities; influences on building energy efficiencies; economic benefits and Life-cycle $\mathrm{CO} 2$ emission analysis will be presented in further research papers. The information provided by this research is believed to 
benefit further researchers, designers and engineers interested in using the most innovative window integrated photovoltaics systems appropriately and correctly.

\section{Acknowledgments}

This work is funded by the Innovate UK Research Project E-IPB-TS/P009263/1-102880. The authors acknowledge the funding agency for its support.

\section{References}

1. Myong, S.Y. and S.W. Jeon, Efficient outdoor performance of esthetic bifacial a-Si:H semitransparent PV modules. Applied Energy, 2016. 164: p. 312-320.

2. Sun, Y., et al., Integrated semi-transparent cadmium telluride photovoltaic glazing into windows: Energy and daylight performance for different architecture designs. Applied Energy, 2018. 231: p. 972-984.

3. Li, X., et al., Optimal design of photovoltaic shading systems for multi-story buildings. Journal of Cleaner Production, 2019. 220: p. 1024-1038.

4. Moran, F. and S. Natarajan, PV in historic dwellings: The potential to reduce domestic CO2 emissions. Journal of Building Engineering, 2015. 3: p. 70-78.

5. IPCC, SPECIAL REPORT ON RENEWABLE ENERGY. 2011.

6. Peng, J., et al., Developing a method and simulation model for evaluating the overall energy performance of a ventilated semi-transparent photovoltaic double-skin facade. Progress in Photovoltaics: Research and Applications, 2016. 24(6): p. 781-799.

7. Wang, M., et al., Comparison of energy performance between PV double skin facades and PV insulating glass units. Applied Energy, 2017. 194: p. 148-160.

8. $\quad$ Peng, J., et al., Validation of the Sandia model with indoor and outdoor measurements for semi-transparent amorphous silicon PV modules. Renewable Energy, 2015. 80: p. 316-323.

9. Cuce, E., P.M. Cuce, and C.-H. Young, Energy saving potential of heat insulation solar glass: Key results from laboratory and in-situ testing. Energy, 2016. 97: p. 369-380.

10. Skandalos, N. and D. Karamanis, Investigation of thermal performance of semi-transparent PV technologies. Energy and Buildings, 2016. 124: p. 19-34.

11. Kapsis, K. and A.K. Athienitis, A study of the potential benefits of semi-transparent photovoltaics in commercial buildings. Solar Energy, 2015. 115: p. 120-132.

12. Cheng, Y., et al., An optimal and comparison study on daylight and overall energy performance of double-glazed photovoltaics windows in cold region of China. Energy, 2019. 170: p. 356-366.

13. Sellami, N., T.K. Mallick, and D.A. McNeil, Optical characterisation of 3-D static solar concentrator. Energy Conversion and Management, 2012. 64: p. 579-586.

14. Sellami, N. and T.K. Mallick, Optical characterisation and optimisation of a static Window Integrated Concentrating Photovoltaic system. Solar Energy, 2013. 91: p. 273-282.

15. Baig, H., et al., Performance analysis of a dielectric based $3 D$ building integrated concentrating photovoltaic system. Solar Energy, 2014. 103: p. 525-540.

16. Chemisana, D. and M. Ibáñez, Linear Fresnel concentrators for building integrated applications. Energy Conversion and Management, 2010. 51(7): p. 1476-1480.

17. Baig, H., N. Sellami, and T.K. Mallick, Trapping light escaping from the edges of the optical element in a Concentrating Photovoltaic system. Energy Conversion and Management, 2015. 90: p. 238-246.

18. Baig, H., N. Sellami, and T.K. Mallick, Performance modeling and testing of a Building Integrated Concentrating Photovoltaic (BICPV) system. Solar Energy Materials and Solar Cells, 2015. 134: p. 29-44. 
19. Ferrer-Rodríguez, J.P., et al., Development, indoor characterisation and comparison to optical modelling of four Fresnel-based high-CPV units equipped with refractive secondary optics. Solar Energy Materials and Solar Cells, 2018. 186: p. 273-283.

20. Tian, M., et al., A review on the recent research progress in the compound parabolic concentrator $(C P C)$ for solar energy applications. Renewable and Sustainable Energy Reviews, 2018. 82: p. 1272-1296.

21. Sellami, N. and T.K. Mallick, Optical efficiency study of PV Crossed Compound Parabolic Concentrator. Applied Energy, 2013. 102: p. 868-876.

22. Cooper, T., et al., Performance of compound parabolic concentrators with polygonal apertures. Solar Energy, 2013. 95: p. 308-318.

23. Pellegrino, A. Traditional and new metrics for effective daylighting design. in Advanced Builidng Skins, Energy Forum. 2013.

24. Sun, Y., Y. Wu, and R. Wilson, Analysis of the daylight performance of a glazing system with Parallel Slat Transparent Insulation Material (PS-TIM). Energy and Buildings, 2017. 139: p. 616-633.

25. Reinhart, C.F. and M. Andersen, Development and validation of a Radiance model for a translucent panel. Energy and Buildings, 2006. 38(7): p. 890-904.

26. Reinhart, C.F. and S. Herkel, The simulation of annual daylight illuminance distributions - a state-of-the-art comparison of six RADIANCE-based methods. Energy and Buildings, 2000. 32(2): p. 167-187.

27. Reinhart, C.F. and O. Walkenhorst, Validation of dynamic RADIANCE-based daylight simulations for a test office with external blinds. Energy and buildings, 2001. 33(7): p. 683697.

28. Ma, P., L.-S. Wang, and N. Guo, Maximum window-to-wall ratio of a thermally autonomous building as a function of envelope $U$-value and ambient temperature amplitude. Applied Energy, 2015. 146: p. 84-91.

29. Acosta, I., M.Á. Campano, and J.F. Molina, Window design in architecture: Analysis of energy savings for lighting and visual comfort in residential spaces. Applied Energy, 2016. 168: p. 493-506.

30. Nabil, A. and J. Mardaljevic, Useful daylight illuminances: A replacement for daylight factors. Energy and Buildings, 2006. 38(7): p. 905-913.

31. Reinhart, C., Daylight performance predictions. Building performance simulation for design and operation, 2011. 1: p. 235-276.

32. CIBSE, C., Code for interior lighting. London: The Chartered Institute of Building Services Engineers, 1994.

33. BRE, BREEAM Hea 1: Visual Comfort

2014, BRE: London

34. Wienold, J. and J. Christoffersen, Evaluation methods and development of a new glare prediction model for daylight environments with the use of CCD cameras. Energy and Buildings, 2006. 38(7): p. 743-757.

35. Wienold, J. Dynamic daylight glare evaluation. in Proceedings of Building Simulation. 2009.

36. Wienold, J. Dynamic simulation of blind control strategies for visual comfort and energy balance analysis. in Building Simulation. 2007. 